\title{
Resepsi Ikatan Keluarga Banyuwangi Terhadap Mantra Sabuk Mangir
}

\author{
Dayu Rahma Dhani ${ }^{\mathrm{a}, 1}$, Vindy Berlian Awanda ${ }^{\mathrm{a}, 2}$, Santi Novitasari ${ }^{\mathrm{a}, 3}$ \\ a Universitas Muhammadiyah Malang, Jalan Raya Tlogomas 246, Malang, Indonesia, 65144 \\ ${ }^{1}$ dayurahmadhani@gmail.com*; ${ }^{*}$ vindywanda@gmail.com; ${ }^{3}$ shantty43@gmail.com
}

\begin{tabular}{ll}
\hline INFO ARTIKEL & ABSTRAK \\
\hline Sejarah Artikel: & Penelitian ini bertujuan untuk mengetahui resepsi yang dilakukan oleh \\
Diterima: 12-08-2019 & Ikatan Keluarga Banyuwangi yang ada di Malang terhadap mantra sabuk \\
Direvisi: - & mangir. Sumber data penelitian ini adalah mahasiswa asal Banyuwangi \\
Disetujui: 18-11-2019 & yang tergabung dalam Ikawangi yang ada di universitas di Malang. \\
& Pengumpulan data dilakukan dengan wawancara. Data yang diperoleh \\
Kata Kunci: & kemudian dianalisis dengan teori resepsi sastra. Hasil penelitian \\
banyuwangi & menunjukkan bahwa pengetahuan generasi muda terhadap mantra sabuk \\
mantra & mangir beragam. Hanya sedikit yang mengerti secara mendalam fungsi \\
resepsi & dan kegunaan mantra ini. Meskipun begitu, bagi mereka yang tidak \\
sabuk mangir & mengerti secara mendalam mempersepsi bahwa mantra ini merupakan \\
& mantra pengasih yang biasa digunakan untuk mencari jodoh. Hal ini \\
& menunjukkan bahwa mantra sabuk mangir di tengah masyarakat \\
& Banyuwangi, khususnya pelajar, tidak banyak lagi diketahui.
\end{tabular}

\begin{tabular}{ll}
\hline & ABSTRACT \\
\hline Keywords: & This study aims to determine the reception conducted by the Ikatan \\
spell & Keluarga Banyuwangi in Malang against the sabuk mangir spell. The data \\
reception & source of this research is students from Banyuwangi who are members of \\
sabuk mangir & Ikawangi at a university in Malang. Data collection is done by interview. \\
& The data obtained were then analyzed with the literary reception theory. \\
& The results showed that the young generation's knowledge of mangir belt \\
& spells varied. Only a few understand deeply the function and usefulness of \\
this mantra. Even so, for those who do not understand deeply perceive \\
that this mantra is a loving mantra commonly used to find a mate. This \\
shows that the sabuk mangir spell in the Banyuwangi community, \\
especially students, is not much known.
\end{tabular}

(C) Cultural Institute, University of Muhammadiyah Malang, Indonesia

\section{PENDAHULUAN}

Setiap daerah memiliki keunikan dan keragaman tersendiri. Begitu juga dengan Banyuwangi yang dikenal oleh sebagian orang sebagai daerah yang mempunyai kepercayaan mengenai hal-hal yang mistis. Budaya masyarakat Osing sering dikenal dengan kekuatan supernatural, gaib, dan magis. Oleh karena itu, budaya santet dan sihir yang marak di kalangan masyarakat Osing tidak lagi dipandang sebagai sesuatu yang menghebohkan. Mantra yang digunakan oleh masyarakat Banyuwangi masih bertahan sampai saat ini yang dimanfaatkan dalam kehidupan sosial oleh masyarakat. (Wulandari, 2017)

Masyarakat Banyuwangi, khususnya masyarakat Osing, merupakan masyarakat yang dipandang oleh sebagian orang sebagai masyarakat yang banyak menggunakan halhal mistis. Hal-hal mistis tersebut dalam masyarakat Banyuwangi sudah dianggap sebagai tradisi dan kesenian. Subaharianto menyatakan bahwa Orang Osing atau 
Banyuwangi diprasangkai sebagai sosok yang kasar dalam hal berbicara, terutama yang terkait dengan hubungan antar-lawan jenis, dan memiliki ilmu gaib destruktif yang disebut santet, pelet, sihir dan sebangsanya (Sutarto, 2006).

Masyarakat Banyuwangi tidak semua yang mempercayai hal-hal tersebut. Masyarakat Banyuwangi yang percaya mengenai hal tersebut sebagian besar ialah masyarakat Osing. Istilah Osing untuk menyebut suatu kelompok etnis dan bahasa lokal di Banyuwangi, pertama kali ditemukan dalam tulisan Lekkerkerker mengenai latar historis ujung timur PuIau Jawa yang terbit pada tahun 1923 (Indiarti, 2016). Kemudian sebagian masyarakat yang tidak mempercayai adalah masyarakat Banyuwangi yang campuran Jawa-Madura.

Masyarakat Banyuwangi sebagian besar beragama Islam. Akan tetapi, masyarakat Banyuwangi juga mempercayai akan hal- hal mistis. Masyarakat Banyuwangi beranggapan bahwa santet dan sejenisnya merupakan sebuah hal sebagai pawang untuk dirinya. Mereka tetap memandang dan bekerja keras menyikapi, mensiasati, dan melakukan negosiasi budaya dengan kekuatan-kekuatan yang hadir menghimpitnya (Maslikatin, 2012).

Masyarakat Banyuwangi mempunyai banyak sekali tradisi, salah satunya ialah mantra sabuk mangir. Sabuk mangir memiliki latar belakang yang bersifat magis. Istilah sabuk mangir merupakan perpaduan dari dua kata, yaitu sabuk berarti ikat pinggang dan mangir merupakan nama sebuah desa di Rogojampi. Sabuk mangir terkenal sebagai sabuk sakti orang Mangir. Berdasarkan kepercayaan bahwa ada kekuatan ghaib yang berada dalam sabuk tersebut. Orang Mangir berusaha melawan musuh-musuhnya, baik musuh yang fisik maupun musuh yang non-fisik menggunakan sabuk ini (Sutarto, 2006).

Sabuk mangir digambarkan dalam sebuah tarian yang menceritakan seseorang yang terkena mantra sabuk mangir kemudian seseorang itu menjadi gila. Mantra atau bacaan merupakan ragam puisi lisan yang berbentuk bebas dan berpotensi memiliki kekuatan gaib (Hidayatulloh, 2017; Sulistyorini \& Andalas, 2017). Seseorang yang terkena sabuk mangir tersebut hanya bisa disembuhkan jika seseorang yang memberikan mantra tersebut meninggal dunia. Kemudian orang yang terkena mantra Sabuk Mangir juga bisa disembuhkan jika mantra tersebut kembali kepada orang yang memberikan mantra dan orang yang memberikan mantra juga bisa gila karena mantra yang diberikan kembali kepada pemberi.

Seiring dengan berjalannya waktu banyak anak muda dari Banyuwangi yang merantau ke Malang untuk mencari ilmu. Dengan semakin banyaknya anak Banyuwangi yang datang ke Malang mereka membuat sebuah perkumpulan bernama Ikawangi (Ikatan Keluarga Banyuwangi). Dalam Ikawangi tidak hanya mahasiswa saja, tetapi dosen ataupun masyarakat Banyuwangi yang ada di Malang yang sudah berkerja pun juga banyak. Ikawangi tersebar di beberapa kampus yang ada di Malang seperti, Universitas Muhammadiyah Malang, Universitas Negeri Malang, Universitas Brawijaya, Universitas Islam Negeri Malik Ibrahim, Universitas Islam Malang, Politeknik Negeri Kesehatan Malang, dan Institut Teknologi Nasional Malang. Dari beberapa kampus tersebut di setiap kampusnya terdapat Ikatan Mahasiswa Banyuwangi yang mempunyai nama yang berbeda-beda. Misalnya di Universitas Muhammadiyah Malang bernama Iwangi, di Universitas Islam Negeri Malik Ibarhim bernama FKMB, dan di Universitas Brwaijaya bernama KMOBM.

Dalam hal mengenai kepercayaan mengenai mantra sabuk mangir. Tentunya tidak semua masyarakat mempercayainya, terutama pelajar Ikawangi yang berada di Malang. Sebagai pelajar tentunya mereka memiliki cara pandang yang sangat kritis dalam memikirkan suatu hal. Begitu juga pandangan mereka mengenai Mantra sabuk mangir. Masalah yang diangkat dalam penelitian ini adalah bagaimana pelajar 
Ikawangi meresepsi keberadaan mantra sabuk mangir?

Penelitian terhadap mantra sabuk mangir sudah pernah dilakukan sebelumnya. Saputra (2007) membahas tentang puisi lisan dan sastra lisan, budaya lokal dan identitas mantra hingga konvensi struktural dan aspek kelisanan. Saputra dan Abdullah (2003) meneliti mengenai konvensi struktural, aspek kelisanan, dan fungsi mantra. Asrumi (2017) meneliti mengenai tradisi basanan dan mantra santet dalam kehidupan sosialbudaya. Berdasarkan hal tersebut penelitian ini belum pernah dilakukan sebelumnya.

Perlunya penelitian ini dilakukan yaitu untuk mengetahui persepsi pelajar Ikawangi mengenai mantra Sabuk Mangir. Karena dengan cara berfikir yang kritis pelajar Ikawangi yang sudah menjadi mahasiswa bisa saja sudah tidak mempercayai mengenai mantra Sabuk Mangir yang menjadi tradisi dari Banyuwangi.

Pendekatan yang digunakan dalam penelitian ini adalah pendekatan resepsi sastra. Karena pada penilitian ini membahas mengenai persepsi pelajar Ikawangi terhadap mantra sabuk mangir. Kemudian teori yang digunakan dalam penelitian ini adalah teori Wolgang Iser yang memfokuskan perhatiannya pada hubungan individual antara pembaca (estetikan pengolahan) dan teks. Secara singkat dapat dikatakan bahwa pembaca implisit merupakan suatu instansi di dalam teks yang memungkinkan terjadinya komunikasi antara teks dan pembacanya (Kamal, 2009).

Penelitian ini menggunakan pendekatan resepsi sastra yang dimaksudkan diarahkan pada pertanyaan mengenai pembaca dalam memberikan makna terhadap karya sastra yang dibacanya, sehingga dapat memberikan reaksi atau tanggapan terhadapnya (Padmopuspito, 1993). Resepsi sastra merupakan pendapat atau tanggapan dari individu-individu dalam menilai sebuah karya sastra dan menghasilkan sebuah tanggapan mengenai karya sastra tersebut.

Menurut Pradopo (Intan, 2017) penelitian terhadap resepsi pembaca dapat dilakukan dengan dua cara, yaitu secara sinkronis dan diakronis. Penelitian sinkronis mempelajari resepsi pembaca dalam periode tertentu terhadap suatu teks sastra. Sedangkan penelitian diakronis mempelajari resepsi pembaca terhadap suatu teks dari periode yang berbeda. Pada penelitian kali ini dilakukan secara sinkronis karena data yang diperoleh dari persepsi pelajar Ikawangi saja tidak membandingkan dengan pendapat orang- orang terdahulu atau orang yang sudah mengerti mengenai mantra Sabuk Mangir.

Dalam penelitian mengenai persepsi Pelajar Ikawangi terhadap Mantra Sabuk Mangir peneliti menggunakan teori Wolfgang Iser yang memfokuskan perhatiannya kepada hubungan individual antara teks dan pembaca (estetikan pengolahan). Pembaca yang dimaksudkan oleh Iser bukanlah pembaca konkrit individual melainkan pembaca implisit (Kamal, 2009). Pembaca implisit merupakan suatu instansi didalam teks yang memungkinkan terjadinya komunikasi antara teks dan pembacanya.

Menurut Iser (Kamal, 2009) karya sastra memiliki dua kutub yakni, kutub artistik dan kutub estetik. Kutub artistik adalah kutub pengarang dan estetik merupakan realisasinya yang diberikan oleh pembaca. Aktualisasi yang benar terjadi didalam interaksi antara teks (perhatian terhadap teknik pengarang, struktur bahasa) dan pembaca (psikologi pembaca dalam proses membaca, fungsi struktur bahasa terhadap pembaca).

Tugas kritik teks ialah mengeluarkan potensi makna yang terdapat di dalam teks tanpa adnaya pembatasan terhadap aspek tertentu (Andalas, 2016a). Hal ini karena teks tidak bersifat statis, tetapi dinamis sehingga dapat berubah sesuai dengan pengalaman pembacanya. Hal tersebut seperti persepsi pelajar Ikawangi yang mempunyai pendapat terhadap mantra Sabuk Mangir. Pendapat tersebut sewaktu-waktu dapat berubah-ubah sesuai dengan pengalaman dan pengetahuan yang dimiliki oleh setiap individu pelajar Ikawangi. 
Iser mengajukan konsep implied reader untuk mengatasi kelemahan pandanganpandangan teoritis mengenai pembaca. Pembaca tersirat sesungguhnya telah dibentuk dan distrukturkan di dalam teks sastra. Teks sendiri telah mengandung syarat-syarat bagi aktualisasi yang memungkinkan pembentukan maknanya dalam benak pembaca (Iser, 1982). Dengan demikian, kita harus mencoba memahami efek tanggapan pembacanya terhadap teks tanpa prasangka tanpa mencoba mengatasi karakter dan situasi historisnya. Teks sudah mengasumsikan pembacanya, entah pembaca yang berkompeten maupun tidak. Teks menampung segala macam pembaca, siapapun dia, karena struktur teks sudah menggambarkan peranannya (Kamal, 2009).

\section{METODE}

Dalam melakukan penelitian mengenai Persepsi Pelajar Ikawangi terhadap mantra sabuk mangir. Jenis penelitian yang digunakan ialah kualitatif. Jenis penelitian ini menggunakan data-data berupa huruf dan tidak terdapat angka sama sekali. Pendekatan penelitian yang digunakan ialah resepsi sastra karena dalam penelitian ini berfokus kepada pada cara membaca dan bagaimana hal tersebut mempengaruhi persepsi pembaca terhadap makna sebuah teks.

Sumber data dalam penelitian ini ialah pelajar Ikawangi. Data penelitian ini berupa hasil wawancara yang berupa rekaman dan hasil tulis dari pendapat pelajar Ikawangi. Teknik pengumpulan data yang digunakan ialah wawancara. Langkah- langkah yang dapat dilakukan seperti (1) menyiapkan pertanyaan (2) mendatangi pelajar ikawangi yang akan diwawancara (3) menulis hasil rekaman dan menandai hal-hal penting, (4) mencatat hasil yang telah ditandai dan akan diulas berdasarkan teori pada bagian pembahasan.

Teknik analisis data yang digunakan ialah deskriptif analitik. Tidak hanya menguraikan, tetapi juga memberikan pemahaman dan penjelasan tentang faktafakta dari persepsi pelajar Ikawangi. Kemudian peneliti melakukan analisis dengan mengaitkan berdasarkan teori. Untuk mengecek keabsahan data, peneliti melakukan triangulasi metode, peneliti, dan teori.

\section{HASIL DAN PEMBAHASAN}

Resepsi dapat diartikan sebagai tanggapan, penerimaan, atau respon. Resepsi sastra berarti tanggapan pembaca terhadap karya sastra. Karya sastra dapat hidup karena partisipasi aktif pembacanya (Jauss, 1983).

Asumsi dasar dari teori yang dikemukakan oleh Wolfgang Iser yang fokus perhatiannya kepada hubungan individual antara teks dan pembaca (estetika pengolahan). Pembaca yang dimaksud ialah pembaca implisit merupakan suatu instansi di dalam teks yang memungkinkan terjadinya komunikasi antara teks dan pembacanya. Hal tersebut seperti yang terdapat pada perepsi pelajar Ikawangi mengenai mantra sabuk mangir.

\section{Resepsi Pembaca Implisit Pelajar Ikawangi}

Keberadaan mantra, sebagai sebagai dari sastra lisan, menempati posisi yang penting dalam kehidupan masyarakat. Hal ini karena produk budaya lisan sering menjadi tempat bagi pandangan dunia masyarakat pemiliknya (Andalas, 2014; 2015; 2018a). Hal ini karena keberadaan produk budaya lisan sering memiliki fungsi tertentu dalam kehidupan masyarakatnya, baik bersifat sakral maupun profan (Andalas, 2016b; 2017a). Begitupun mantra sabuk mangir bagi masyarakat Banyuwangi.

Dengan berbagai perkembangan modernisasi yang terjadi saat ini, keberadaan produk budaya ini tidak lagi sama seperti dahulu (Andalas, 2018b). Hal ini karena dalam arus modernisasi berbagai paham, pengaruh, dan produk yang berasal dari luar dapat mempengaruhi persepsi dan cara pandang masyarakat pemilik kebudayaan terhadap produk budayanya.

Seorang responden, $\mathrm{FH}$, seorang mahasiswa Universitas Brawijaya jurusan Pemanfaatan Sumber Daya Perikanan 
meresepsi mantra sabuk mangir sebagai berikut.
"saya mengetahui mantra sabuk mangir dari cerita mbah buyut saya. Mantra Sabuk Mangir sering digunakan para kaum yang sendiri untuk mencari pasangan agar cepat mendapatkan pendamping. Mantra sabuk mangir pada zaman sekarang sudah diketahui oleh banyak orang dan juga banyak orang yang sudah menggunakan mantra mantra sabuk mangir. Menurut saya mantra sabuk mangir merupakan sebuah hal yang menyimpang karena sudah keluar dari ajaran agama"

Pendapat tersebut memperlihatkan mengenai pola berpikir yang dilandaskan pada peresepsian mantra dalam posisinya terhadap kaidah keagamaan. FH tidak melihat mantra sabuk mangir dalam posisinya sebagai sebuah produk budaya masyarakat Banyuwangi semata. Hal ini didukung oleh argumentasinya yang menjelaskan bahwa terdapat citra negatif yang melekat pada mantra ini.

Pandangan ini memperlihatkan hal yang disebut oleh Sugiarti \& Andalas (2018) bahwa sebagai sebuah kitab pembelajaran moral, keberadaan karya sastra tidak bisa dilepaskan dari dimensi kemasyarakatan tempat karya sastra tersebut diciptakan juga tidak bisa dilepaskan dari kondisi zaman tempat karya sastra tersebut ditafsirkan. Artinya, FH menempatkan posisi mantra sabuk mangir dalam konteks masyarakat modern saat ini. Terlebih dengan pendidikan yang dijalaninya memberikan pengaruh terhadap penggunaan pola berpikir rasional dalam menafsirkan keberadaan mantra sabuk mangir.

Seorang responden lain, MRAH, mahasiswa Universitas Muhammadiyah Malang jurusan Teknik Informatika mengemukakan pandangannya berikut.

"menurut saya mantra sabuk mangir tersebut biasanya dilantunkan sebelum pertunjukkan tari sabuk mangir. Saya juga percaya menenai adanya mantra tersebut karena saya sendiri pernah melihat orang yang terkena mantra tersebut. Orang yang saya lihat ketika terkena mantra sabuk mangir seperti menggilai seseorang. Tetapi saya belum tahu bagaimana cara agar orang yang terkena mantra sabuk mangir bisa sembuh".

Sudut pandang yang digunakan oleh MRAH tampak berbeda dengan responden pertama. MRAH memandangnya sebagai sebuah bentuk kearifan lokal yang memang dipercayai keberadaannya meskipun secara langsung ia mengakui tidak memahaminya atau mengalaminya secara langsung. Ia menuturkan pernah melihat orang yang terkena mantra tersebut. Keberadaan mantra sabuk mangir sebagai bagian dari kearifan lokal masyarakat Banyuwangi dalam jawaban tersebut perlu dilihat sebagai bentuk kesadaran terhadap sejumlah tata nilai masyarakat Banyuwangi dalam memandang kehidupan di sekitarnya (Ariani \& Andalas, 2019).

Pandangan antara MRAH dan FH memperlihatkan dua hal yang saling bertolak belakang. Meskipun begitu, terdapat argumentasi yang dapat dijadikan landasan dalam memahami perbedaan peresepsian terhadap keberadaan mantra sabuk mangir di tengah masyarakat Banyuwangi. Pada pendapat pertama, pengedepanan terhadap aspek pada rasionalitas dan ajaran keagamaan tampak lebih kuat dibandingkan pada pendapat kedua. Pada pendapat kedua, meskipun sebagai seorang pelajar yang sama dengan responden pertama, tetapi kuatnya nilai-nilai tradisi yang mengikat dalam kehidupan kulturalnya (Iman \& Andalas, 2019) serta pengalaman melihat secara langsung peristiwa seseorang yang terkena akibat dari mantra tersebut memberikan perspektif yang berbeda.

Pendapat tersebut diperkuat oleh responden ketiga $\mathrm{RG}$, mahasiswa Universitas Muhamamadiyah Malang 
jurusan Teknik Informatika yang berpendapat sebagai berikut.

"saya mempercayai adanya mantra sabuk mangir karena di Banyuwangi sendiri masih banyak kejadian-kejadian mengenai mantra sabuk mangir. Tetapi saya berpendapat bahwa sabuk mangir itu merupakan sebuah hal yang menyalahi syariat agama, dengan memaksa orang menjadi jodohnya. Fungsi lain yang saya ketahui dari mantra sabuk mangir, yaitu semacam susuk biasanya digunaka atau disisipkan dibedak penari, agar penonton tertarik kepada sang penari”.

Berbagai hal tersebut memperlihatkan bahwa terdapat peran dari pendidikan budaya yang diperoleh secara tidak langsung oleh berbagai pelajar tersebut sejak kecil sehingga mempengaruhi persepsinya dalam menjabarkan realitas yang ditemuinya pada saat dewasa. Hal ini secara tidak langsung dipengaruhi oleh wujud unconscious whises, yaitu harapan dari tataran nirasadar yang mengendap dalam alam bawah sadar masing-masing responden (Andalas, 2017b). Respon kedua dan ketiga menafisirkan keberadaan mantra sabuk mangir dengan realitas kehidupan kultural pada masyarakat tempatnya tinggal. Kuatnya pengaruh emosi kultural ini mendorongnya untuk menafsirkan realitas yang ada tidak hanya didasarkan pada tata nilai rasionalitas dan modernitas yang dijalaninya saat ini sebagai mahasiswa di Malang.

\section{Resepsi Ikawangi yang Tidak Mengetahui Mantra Sabuk Mangir}

Selain repsonden yang mengetahui secara baik keberadaan mantra sabuk mangir, juga dilakukan respondensi terhadap pelajar Ikawangi yang mengaku tidak mengetahui tentang keberadaan mantra ini. Atau setidaknya dia belum pernah melihat secara langsung eksistensi mantra ini.

Seorang Responden berinisial RK, seorang mahasiswa jurusan Manajemen
Universitas Muhammadiyah Malang mengatakan bahwa meskipun mayoritas masyarakat di sekitar tempat tinggalnya adalah suku Osing, tetapi ia tidak mengetahui mantra sabuk mangir yang asli. Ia hanya mempercayai bahwa fungsi mantra tersebut tergantung pemakainya. Namun, mantra sabuk mangir adalah ilmu pangasihan umumnya masyarakat menggunakannya untuk memikat lawan jenisnya dan selain itu fungsi lainnya seperti untuk melindungi diri, biasanya digunakan oleh orang yang mempunyai usaha agar terhindar dari santet.

Mantra sabuk mangir dan jaran goyang adalah mantra yang berfungsi sama sebagai pengasih, namun yang membedakannya adalah mantra sabuk mangir mempunyai kitab dan kitab tersebut sampai sekarang masih ada dan menggunakan suatu media.

Hal ini sejalan dengan BI, alumni jurusan Pendidikan Bahasa Inggris Universitas Muhammadiyah Malang yang mengatakan bahwa mayorits penduduk yang ada di wilayahnya beretnis Jawa. Menurut Rinas mantra tersebut ada tetapi ia tidak meyakininya dan juga ia mengatakan bahwa mungkin masih ada yang menggunakannya tetapi minoritas saja. Ia tidak mengetahui keberadaan mantra tersebut. Meskipun pada satu sisi ia mempercayai adanya keberadaan mantramantra dalam masyarakat, tetapi ia tidak pernah menyaksikannya secara langsung.

Pendapat kedua responden tersebut memperlihatkan bahwa, baik berasal dan tinggal pada masyarakat lingkungan suku Osing ataupun Jawa, tidak semerta-merta mempengaruhi mereka dalam memahami atau mengetahui keberadaan mantra sabuk mangir. Memang, jika diperhatikan secara lebih mendalam, terdapat beragam faktor yang mempengaruhi pengetahuan budaya ini, seperti latar sosial, budaya, ekonomi, dan pendidikan (Pratiwi., Andalas., \& Dermawan, 2017). Akan tetapi, hal ini menegaskan mengenai posisi dari mantra sabuk mangir dalam kehidupan masyarakat Banyuwangi saat ini. Hal ini utamanya 
pada pelajar yang saat ini tinggal di Malang.

\section{KESIMPULAN}

Dari penelitian yang dilakukan dapat disimpulkan bahwa keberadaan mantra sabuk mangir saat ini tidak lagi setenar pada zaman dahulu. Meskipun begitu, terdapat beberapa kelompok yang masih mempercayai keberadaan mantra dan fungsinya ataupun kelompok yang sama sekali tidak mengetahui dan mempercayai fungsinya dalam kehidupan masyarakat saat ini. Dari hasil wawancara yang telah dilakukan mantra sabuk mangir sudah dikenal oleh banyak orang yang bertempat tinggal di daerah suku Osing, tetapi hanya beberapa orang yang memang mengerti secara mendalam mengenai mantra sabuk mangir seperti halnya fungsi, kegunaan, dan cara penyembuhan bagi orang yang terkena mantra sabuk mangir. Bagi kelompok masyarakat yang tidak memahami atau mengenal mantra ini mantra sabuk mangir dipahami sebagai mantra pengasih untuk mencari jodoh.

\section{REFERENSI}

Andalas, E. F. (2014). Mitos Mbah Bajing dalam Sastra Lisan Masyarakat Dusun Kecopokan Kecamatan Sumberpucung Kabupaten Malang. Skripsi tidak Diterbitkan. Malang: Universitas Negeri Malang.

Andalas, E. F. (2015). Mitos-Mitos Kabupaten Malang: Cara Orang Jawa dalam Menjelaskan Dunianya. Puitika, 11(2), 150-162.

Andalas, E. F. (2016a). Citra Antikolonial dalam Film Avatar (2009): Sebuah Tinjauan Poskolonial. Puitika Jurnal Humaniora, 12(1), 1-10.

Andalas, E. F. (2016b). Sastra Lisan Lakon Lahire Panji dalam Pertunjukan Wayang Topeng Malangan Padepokan Mangun Dharma: Kajian Sastra Lisan Ruth H Finnegan. Universitas
Airlangga.

Andalas, E. F. (2017a). Dampak dan Fungsi Sosial Mitos Mbah Bajing bagi Kehidupan Spiritual Masyarakat Dusun Kecopokan Kabupaten Malang Jawa Timur. Puitika, 13(1), 20-31.

Andalas, E. F. (2017b). Eskapisme Realitas Dalam Dualisme Dunia Alice Telaah Psikologi-sastra Film Alice in Wonderland (2010). KEMBARA: Jurnal Keilmuan Bahasa, Sastra, dan Pengajarannya, 3(2), 185-195.

Andalas, E. F. (2018a). Cerita Rakyat dan Tradisi Masyarakat Agraris Nusantara: Mitos Dewi Sri (Jawa) dan Legenda Putri Mandalika (Sasak). In P. Karyanto (Ed.), Kisah-Kisah Perempuan dan Cerita Rakyat Nusantara (pp. 1-12). Surabaya: Kajian Sastra dan Budaya Universitas Airlangga.

Andalas, E. F. (2018b). Meninjau Kembali Identitas Budaya Jawa di Era Globalisasi. In Seminar Kebudayaan Jawa (pp. 1-12).

Ariani, M. F., \& Andalas, E. F. (2019). Kearifan Lokal Malangan dalam Kumpulan Cerpen Aloer-Aloer Merah Karya Ardi Wina Saputra. JURNAL SATWIKA, 2(2), 108-118.

Asrumi, A. (2017). Tradisi Basanan dan Mantra Santet Osing sebagai Wujud Kearifan Lokal dalam Meredam Konflik (Tinjauan semantik: Studi Kasus di Banyuwangi).

Hidayatullah, D. (2017). Mantra dalam Naskah "Doa Wirid Tolak Bala": Deskripsi, Isi, dan Suntingan Teks. Kandai, 13(1), 121-136.

Iman, N., \& Andalas, E. F. (2019). Representasi Kehidupan Religius Masyarakat Islam Kejawen Di 
Yogyakarta Pada Tahun 1868 M-1912 M dalam Novel Dahlan: Sebuah Novel Karya Haidar Musyafa. Pena Literasi, 2(1), 189-200.

Indiarti, W. (2016). Masa Lalu Masa Kini Banyuwangi: Identitas Kota dalam Geliat Hibriditas dan Komodifikasi Budaya di Perbatasan Timur Jawa. In International Conference "Indonesia: Art and Urban Culture (pp. 1-19).

Intan, T. (2017).Studi Terhadap Resepsi Pembaca Perempuan Pada Novel Romantis Berbahasa Indonesia dan Perancis dengan Konsep Reading TheRomance dari Janice Radway. Bandung: Universitas Padjadjaran. Disertasi.

Kamal, Y. (2009). Teori Sastra. Jurusan Bahasa dan Sastra Arab. IAIN Sunan Ampel Surabaya

Maslikatin, T. (2012). Kerudung Santet Gandrung Dialektika Sastra Dan Tradisi Sub-Kultur Masyarakat UsingBanyuwang. Prosiding Seminar Internasional Hiski. Jember: Fakultas Sastra Universitas Jember.

Padmopuspito, A. (1993). Teori Resepsi dan Penerapannya. Jurnal Diksi (2) 1.

Pratiwi, Y., Andalas, E. F., \& Dermawan, T. (2017). Penelitian Sastra Lisan Kontekstual: Performance-CenteredApproach. Malang: Kota Tua.

Saputra, H. S. P. (2007). Memuja mantra: sabuk mangir dan jaran goyang masyarakat suku Using Banyuwangi. PT LKiS Pelangi Aksara

Saputra, H. S. P., \& Abdullah, I. T. (2003). Mantra Sabuk Mangir dan Jaran Goyang dalam budaya Using di Banyuwangi (Doctoral dissertation, Universitas Gadjah Mada). Tesis
Sugiarti, S., \& Andalas, E. F. (2018). Pespektif Etik dalam Penelitian Sastra. Malang: UMM Press.

Sulistyorini, D., \& Andalas, E. F. (2017). Sastra Lisan: Kajian Teori dan Penerapannya dalam Penelitian. Malang: Madani.

Sutarto, A. (2006). Sekilas Tentang Masyarakat Using. Pembekalan Jelajah Budaya 2006, Balai Kajian Sejarah dan Nilai Tradisional Yogyakarta, pp. 1-13.

Wulandari, I. dkk. (2017). Simbolisme Mantra Semar Mesem Terhadap Kekuasaan Di Banyuwangi. Bali: Universitas Udayana. 